\title{
A Case Study of Trust Issues in Scientific Video Collections
}

\author{
Emma Beauxis-Aussalet, Elvira Arslanova, Lynda Hardman, \\ Jacco Van Ossenbruggen \\ CWI \\ Information Access Group \\ Amsterdam, The Netherlands \\ \{emma, elvira, lynda.hardman, jacco.van.ossenbruggen\}@cwi.nl
}

\begin{abstract}
In-situ video recording of underwater ecosystems is able to provide valuable information for biology research and natural resources management, e.g. changes in species abundance. Searching the videos manually, however, requires costly human effort. Our video analysis tool supports the key task of counting different species of fish, allowing marine biologists to query the video collection without watching the videos. To be suitable for scientific research on changes in species abundance, the video data must include data provenance information that reflects the potential biases introduced through the video processing.In order to trust the analyses made by the system, we need to provide expert users with sufficient information to allow them to interpret these potential biases. We conducted two user studies to design a user interface that includes data provenance information. Our qualitative analysis discusses the support for understanding the reliability of video analysis, and trusting the results it produces. Our main finding is that disclosing details about the video processing and provenance data allows biologists to compare the results with their traditional statistical methods, thus increasing their trust in the results.
\end{abstract}

\section{Categories and Subject Descriptors}

H.5.1 [Information Interfaces and Presentation]: Multimedia Information Systems - Video, Evaluation/Methodology; H.5.2 [Information Interfaces and Presentation]: User Interfaces

\section{General Terms}

Design; Human Factors; Reliability

\section{Keywords}

Data Provenance; Video Analysis; Information Design

Permission to make digital or hard copies of all or part of this work for personal or classroom use is granted without fee provided that copies are not made or distributed for profit or commercial advantage and that copies bear this notice and the full citation on the first page. Copyrights for components of this work owned by others than the author(s) must be honored. Abstracting with credit is permitted. To copy otherwise, or republish, to post on servers or to redistribute to lists, requires prior specific permission and/or a fee. Request permissions from permissions@ acm.org. MAED'13, October 22, 2013, Barcelona, Spain.

Copyright is held by the owner/author(s). Publication rights licensed to ACM. ACM 978-1-4503-2401-4/13/10 ...\$15.00.

http://dx.doi.org/10.1145/2509896.2509907 .

\section{INTRODUCTION}

The Fish4Knowledge project has been continuously recording video footage of coral reef fish from a number of underwater cameras since 2010. This collection has motivated the development of a tool for automatically recognizing fish from different species, addressing the scientific study of marine ecosystems. Serious scientific study demands the disclosure of the data collection method and its possible biases. In our case, the original video data is processed within a framework that consists of 3 video analysis components. From a biologist's perspective, each component potentially introduces biases in the scientific findings that can be drawn from the video data. This study focuses on the requirements for the design of a video analysis tool delivering provenance information that is sufficient for supporting the valid scientific analysis of the video collection. We explored the following research question: What provenance information is necessary for users to trust the system and accept it for their research? We conducted a case study focused on: i) the limitations of video analysis compared to other data collection methods; ii) the usage of well-accepted scientific methods to cope with potential biases; iii) the human-computer interaction means to present understandable provenance information; and iv) the potential impact of introducing ROC evaluation in the provenance information. Our insights are relevant for solving trust issues encountered with similar video analysis tools delivering provenance information for scientific video collections in fields.

\section{RELATED WORK}

Trust - A number of models and scales were used to measure Human-Computer Trust (HCT) in different computational systems [1]. In this study we adapted the trust definition from [7] and [9]: Trust is the extent to which a user is confident in, and willing to use the data produced by the video analysis software. This definition indicates two major factors contributing to HCT: confidence and willingness to use the software. These factors are influenced by cognitionand affect-based components of HCT. Specifically, cognitivebased components of HCT are impacted by the explanations provided by the software $[8,12]$.

Data Provenance - It is becoming common that research is done on data collected by others. In these cases, the data provenance concerns the systematic recording of the derivation history of each data item, starting from its original sources. These records are often of crucial importance for a researcher to decide if the data is suitable. It is also neces- 


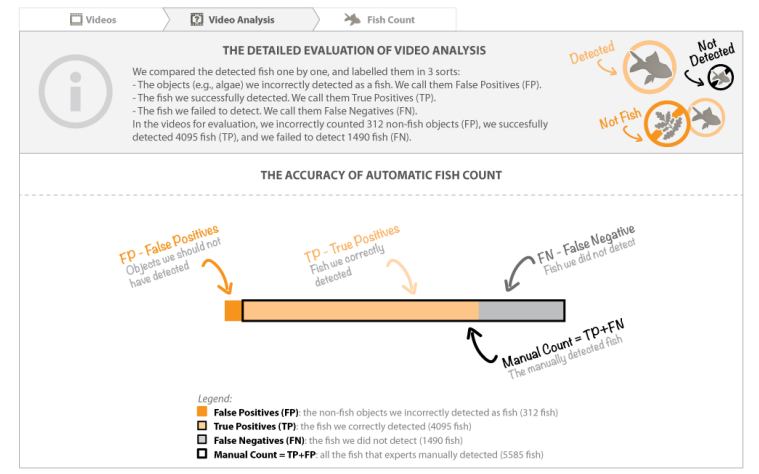

Figure 1: A version of the performance measure shown to participants.

sary to be able to replicate the data if needed. [11] provides an extensive overview on the topic. Tool support for maintaining data provenance is common in scientific workflow systems such as Kepler [6] and Taverna [10]. W3C recently developed a common model and metadata format to express and exchange provenance information, see the PROV Ontology [5] for more information. Use cases of data provenance for the biology and image processing domains can be found in $[2,3,4]$.

\section{EXPERIMENTAL SET-UP}

We recruited 11 participants (2 professors, 8 researchers, 1 master student) working in the biology research domain from Greece, the Netherlands and Taiwan, by using the snowball technique. We used a semi-structured interview followed by an experiment with an online interface. 4 participants were not able to complete the experiment, but completed the interview.

Semi-structured interviews - We asked participants about their topics of research, their information needs, their current data collection practices and corresponding potential biases, and their envisaged usage of our video analysis tool. Early user interviews were reported in a project deliverable $^{1}$. User interviews were transcribed and independently interpreted by two of the authors. Interpretations were compared and synthesized into 7 typical cases, as summarized in Table 1. We focused on the comparison of implicit biases associated with the different data collection methods. This is useful to understand how users are likely to deal with the potential biases introduced by video analysis.

Experiment - We exposed participants to 3 experimental versions of the video analysis system with different measures of its performance, e.g. Fig. 1. The experimental system shown to participants concerned detecting and counting fish. The performance measures consisted of comparing automatic detections with manual detections from a groundtruth. We introduced the basic technical concepts which are necessary to understand the measure. These are introduced with gradually increasing levels of complexity, in 3 subsequent versions. The 1st version introduced the concept of ground-truth. It presented the manual and automatic fish counts, and the number of videos in the ground-truth

\footnotetext{
${ }^{1}$ http://homepages.inf.ed.ac.uk/rbf/Fish4Knowledge/ DELIVERABLES/Del21.pdf
}

dataset and in the large overall collection. The 2nd version, illustrated by Fig. 1, introduced the concepts of True Positive, False Negative and False Positive (True Negatives were not used for the evaluation of fish detection since they are not constant across the versions of the video analysis software). The $3 \mathrm{rd}$ version introduced the concepts of feature vectors and similarity thresholds of classifiers. The measure was presented as the comparison of each fish image with a fish model. The provenance information provided a set of fish counts produced by using different thresholds on the feature vectors.

After each version, participants completed a questionnaire aiming at evaluating 4 aspects of the user experience: i) the global user trust in the video analysis tool; ii) the user acceptance of the video analysis tool; iii) the user understanding of the technical concepts; and iv) the satisfaction of the user information need for data provenance. Participants were asked to assume the role of a biologist interested in trends in fish populations during 2011. They were asked to identify trends in the video data (e.g., small, or big increases in fish counts) that include the data provenance information introduced in the current step. They were also asked technical questions, so as to measure their understanding of the technical concepts. Lastly, they were asked rated questions that measured their trust in the tool, the acceptance of the tool's imperfection, and the satisfaction of their information needs. We analyzed participants' answers by using a 4-grade scale to qualify their trust, acceptance, understanding, and the satisfaction of their information needs, as reported in Table 3 .

\section{ANALYSIS OF THE INTERVIEWS}

Case 1 - 1 participant - The team based in The Netherlands studies Caribbean reef fish, e.g., the distribution of specific species and its variation over time (e.g., population dynamics and migrations). They use baited stereoscopic cameras to count fish, identify their species and evaluate their size. They use vessels to collect video samples at singlepoint locations that cover the areas and periods of interest. They manually identify single fish, without duplicates, by analyzing only one frame per video sample. They select the frame with the most fish. The uncertainties caused by occlusions are resolved by browsing other video frames. Their existing method is satisfactory, but the manual image analysis is time-consuming. They would potentially use video analysis tools for automatically counting fish and identifying species, with the same sampling method using the most dense frame. The uncertainty issues introduced by video analysis are easily accepted because the cost reduction is important.

Case 2 - 3 participants - The team based in The Netherlands studies North Sea deep-water corals and seabed ecosystems, e.g., the distribution of species in the various deep sea habitats, and the related trophic systems (i.e., food chain). They use cameras held by a line just above the seabed, and moved in transects (lines) within the areas of interest. A laser measures the exact distance between the camera and the seabed. It serves to calibrate the measurement of fish size. They manually identify each organism and habitat features (e.g., rocks), and measure their size. The organisms are very sparse and noticeable on the empty seabed surface, but they encounter uncertainties with respect to species identification and cryptic (hidden or camouflaged) 
Table 1: Summary of the studied cases

\begin{tabular}{|c|c|c|c|c|c|c|}
\hline & Data & Data Collection & $\begin{array}{l}\text { Sampling } \\
\text { Method }\end{array}$ & Uncertainty Issues & $\begin{array}{l}\text { Research } \\
\text { Topic }\end{array}$ & $\begin{array}{l}\text { Potential video } \\
\text { analysis }\end{array}$ \\
\hline 2 & $\begin{array}{l}\text { Fish count, } \\
\text { Species, } \\
\text { Size, Other } \\
\text { objects }\end{array}$ & $\begin{array}{l}\text { Video Images: } \\
\text { lighted camera held } \\
\text { close to deep sea } \\
\text { floor, calibration of } \\
\text { distance to seabed, } \\
\text { manual analysis }\end{array}$ & $\begin{array}{l}\text { Transects } \\
\text { (along a } \\
\text { virtual } \\
\text { line) }\end{array}$ & $\begin{array}{l}\text { Rare misidentification of } \\
\text { species. Cryptic organ- } \\
\text { isms. }\end{array}$ & $\begin{array}{l}\text { Population Dy- } \\
\text { namics, Trophic } \\
\text { Systems }\end{array}$ & $\begin{array}{l}\text { To avoid manual } \\
\text { image analysis in } \\
\text { current practices. } \\
\text { To reduce expensive } \\
\text { vessel usage. }\end{array}$ \\
\hline 3 & $\begin{array}{l}\text { Fish count, } \\
\text { Species, Size }\end{array}$ & $\begin{array}{l}\text { Diving } \\
\text { tions, } \\
\text { camera for bandherva- } \\
\text { purposes }\end{array}$ & $\begin{array}{l}\text { Transects } \\
\text { (at } \\
\text { varying } \\
\text { depths) }\end{array}$ & $\begin{array}{l}\text { Species misidentification. } \\
\text { Some species are hiding } \\
\text { from divers. Overlapping } \\
\text { fish in groups. }\end{array}$ & $\begin{array}{l}\text { Population Dy- } \\
\text { namics, Trophic } \\
\text { Systems }\end{array}$ & $\begin{array}{l}\text { To analyze existing } \\
\text { videos. To avoid } \\
\text { diving. }\end{array}$ \\
\hline 5 & $\begin{array}{l}\text { Fish count, } \\
\text { Species, Size, } \\
\text { Weight }\end{array}$ & $\begin{array}{l}\text { Commercial Fish- } \\
\text { ery: data for North- } \\
\text { Sea fish market }\end{array}$ & $\begin{array}{l}\text { Dependent } \\
\text { on com- } \\
\text { mercial } \\
\text { fisheries }\end{array}$ & $\begin{array}{l}\text { Variability of fish catch. } \\
\text { Only commercial species } \\
\text { are targeted. Uncommon } \\
\text { species are misidentified. }\end{array}$ & $\begin{array}{l}\text { Population Dy- } \\
\text { namics, Migra- } \\
\text { tion, Reproduc- } \\
\text { tion }\end{array}$ & $\begin{array}{l}\text { To compensate the } \\
\text { biases in the market- } \\
\text { dependent sampling }\end{array}$ \\
\hline 6 & $\begin{array}{l}\text { Fish count, } \\
\text { Species, Size }\end{array}$ & $\begin{array}{l}\text { Diving Observa- } \\
\text { tions }\end{array}$ & $\begin{array}{l}\text { Single- } \\
\text { point } \\
\text { loca- } \\
\text { tions or } \\
\text { transects }\end{array}$ & $\begin{array}{l}\text { Species misidentification. } \\
\text { Some species are hiding } \\
\text { from divers. Overlapping } \\
\text { fish in groups. }\end{array}$ & $\begin{array}{l}\text { Population Dy- } \\
\text { namics, Trophic } \\
\text { systems, Repro- } \\
\text { duction, Envi- } \\
\text { ronmental event }\end{array}$ & To avoid diving. \\
\hline
\end{tabular}

Table 2: Information needs for biology research topics, and ability of data collection method to address these needs. Video images do not provide the most reliable information.

\begin{tabular}{|c|c|c|c|c|}
\hline & Fish Counts & $\begin{array}{l}\text { Species Iden- } \\
\text { tification }\end{array}$ & $\begin{array}{l}\text { Behaviour } \\
\text { Identification }\end{array}$ & Fish Body Size \\
\hline \multicolumn{5}{|l|}{ Research Topic } \\
\hline Population Dynamics & mandatory & mandatory & optional & important \\
\hline Trophic Systems & mandatory & mandatory & important & important \\
\hline Reproduction & mandatory & mandatory & important & important \\
\hline Migration & mandatory & mandatory & optional & optional \\
\hline Environmental Event & $\begin{array}{l}\text { mandatory to } \\
\text { optional }\end{array}$ & mandatory & $\begin{array}{l}\text { mandatory to } \\
\text { optional }\end{array}$ & mandatory to optional \\
\hline \multicolumn{5}{|c|}{ Data Collection Method } \\
\hline Commercial Fishery & + & + & - & + \\
\hline Experimental Fishery & + & + & - & + \\
\hline Diving Observation & ++ & + & ++ & + \\
\hline Fish Dissection & - & ++ & - & ++ \\
\hline Video Image & + & + & + & $\begin{array}{l}+/- \text { (if stereoscopic or } \\
\text { calibrated vision) }\end{array}$ \\
\hline
\end{tabular}

The above signs indicate that the data collection:

+ can supply the information, - can not supply the information, ++ can supply the most reliable information. 
organisms. A video browsing tool allows them to manually extract object size by using the size measured in pixels and the camera to seabed distance. The observations and measures are manually collected in spreadsheet files. Their existing method is satisfactory, but the manual image analysis is extremely time-consuming and the vessel is very expensive. They would potentially use a video analysis tool for automatically identifying objects in their video collection, or for designing cheaper data collection methods.

Case 3 - 1 participant - The team based in The Netherlands focuses on commercial fisheries. They study the abundance, distribution, and trophic systems of the Philippines' coral reef fish, and their vulnerability to fishing. They collect diving observations along transects at varying depth. Video cameras are used for backup purposes and occasional refinements of the live observations. The analysis of the diving notes and videos is entirely manual. They encounter uncertainty issues with the missed detection, since many organisms occur simultaneously. They usually approximate the number of fish in dense fish groups with many overlaps. The observable species are different depending on the depth, and it requires an extensive taxonomic knowledge and sample collection to cover their diversity. The data collection method is satisfactory but costly and time-consuming, which limits the quantity of samples. They would potentially use video analysis tools for browsing the video collection, or for designing new data collection methods.

Case 4 - 1 participant - The team based in Greece studies population dynamics, trophic systems, reproduction and physiology of pelagic fish living in the Aegan Sea. They sample and dissect fish from experimental fisheries, as commonly practiced in the marine biology domain. They collect fish at single-point locations or following a stratified sampling method. Fish dissection provides precise identification of look-alike species, and precise measurements of age, fertility and feeding habits. They encounter uncertainty regarding the replicability of fish catch. Fish catches performed under the same conditions (e.g., one after the other) provide highly variable results. This issue is overcome by collecting a sufficient number of samples following accepted sampling methods. This data collection method is costly but satisfactory. Their acceptance of our tool is low because: i) video analysis cannot supply all the data they need, ii) they need a different sampling of the areas of interest, and iii) video analysis introduces uncertainties they can avoid with their existing method.

Case 5 - 2 participants - Their separate teams, based in The Netherlands, conduct similar studies of population dynamics in the North Sea. They collect fish counts from commercial fisheries, as practiced for decades in the marine biology domain. The large amount of available data supports the study of population dynamics, migration and reproduction. Commercial fisheries target only specific species. Thus they encounter uncertainty issues with respect to the uneven sampling of species, areas, depths and environmental conditions. Unusual species are often misidentified, but the amount of data allows statistical methods to overcome this issue. This data collection method is satisfactory, but could be complemented by video analysis tools for compensating the sampling biases.

Case 6 - 2 participants - Their separate teams, based in Taiwan and The Netherlands, conduct similar studies of coral reef ecosystems. They study population dynam- ics, interactions between species (trophic systems, reproduction), migration patterns, and vulnerability to environmental changes. They collect fish counts, species identification and approximated fish size from diving observations. They collect data at single-point locations or in transects. They encounter uncertainty issues regarding missed detections, multiple detection of single fish, species misidentification, and some species are likely to avoid divers, thus biasing the collected data. These issues are tackled by methods to evaluate the potential errors, such as comparing data from different sources. They would potentially use video analysis tools to reduce data collection costs, and for collecting larger numbers of samples.

Case 7 - 1 participant - The team based in The Netherlands studies population dynamics and the vulnerability of the Wadden Sea fish to fisheries. They collect data from industrial waste of commercial fisheries. This data collection method is currently under development. It uses common CCTV cameras to record individuals falling out of the nets, or being discarded during industrial fish sorting. They manually count fish and identify species, while they are developing video analysis software to address this task. With their video analysis tool, they encounter important uncertainty issues regarding the misidentification of species and non-fish objects. This is due to the speed at which fish pass by the camera during industrial processes.

\section{ANALYSIS OF THE EXPERIMENT}

Trust - Most participants did not trust the tool. The details introduced at Step 2, using version 2 of the explanation, Fig. 1, did not improve user trust. At Step 3, however, user trust was improved in 4 cases out of 7 , and worsened in 1 case. The most skeptical participants showed a very good understanding of the technical details (cases 6a, 6b, 7a), whereas the most confident participants showed a poor understanding (cases 2, 4 and 7b).

Acceptance - Most participants would accept to use the tool for scientific purposes, even though the presentation stated that the evaluated count missed $27 \%$ of the fish. The details introduced at Step 2 had no major impact, but at Step 3 acceptance was improved in 2 cases. All participants answered that amongst the 3 presentations they would choose to work with the provenance information of the 3rd step. The availability of alternative fish counts for several thresholds was important for participants, as they can choose the most appropriate threshold for their case (e.g., "I want you to give me as many lines as possible and I will decide which one to use"). All participants that were already using videos in their research showed a high level of acceptance (cases 2-4). The most reticent participants showed a low level of trust (cases 6a and 7a).

Understanding - At all steps, most participants had difficulties understanding the technical concepts in the presentation. We also observed many misunderstandings of the technical questions of the questionnaires. They needed a long time to think, to read the explanations several times, and extra oral explanations. Most participants showed difficulties with recalling the definition of new terms we introduced (e.g., False Positives). Step 1 was better understood but its basic concepts were not grasped by 2 participants. The participants with an excellent understanding were already familiar with the technical concepts (cases 6a-6b). 
Table 3: Qualitative analysis of the experiment

\begin{tabular}{|c||c|c|c||c|c|c||c|c|c||c||c|c||}
\cline { 2 - 17 } \multicolumn{1}{c|}{} & \multicolumn{4}{c|}{ Trust } & \multicolumn{3}{c||}{ Acceptance } & \multicolumn{3}{c||}{ Understanding } & \multicolumn{3}{c||}{ Information Need } \\
\hline Case & Step 1 & Step 2 & Step 3 & Step 1 & Step 2 & Step 3 & Step 1 & Step 2 & Step 3 & Step 1 & Step 2 & Step 3 \\
\hline \hline 2 & + & + & - & + & + & + & - & - & - & ++ & ++ & ++ \\
\hline 3 & - & - & + & + & + & + & + & - & + & ++ & + & + \\
\hline 4 & ++ & ++ & ++ & ++ & ++ & ++ & + & -- & -- & + & + & ++ \\
\hline $6 \mathrm{a}$ & - & - & - & - & - & - & ++ & ++ & ++ & + & + & + \\
\hline $6 \mathrm{~b}$ & -- & -- & - & + & + & ++ & ++ & ++ & ++ & ++ & ++ & ++ \\
\hline $7 \mathrm{a}$ & -- & -- & - & - & - & - & + & + & - & ++ & ++ & ++ \\
\hline $7 \mathrm{~b}$ & + & - & + & + & + & ++ & -- & -- & - & ++ & - & + \\
\hline
\end{tabular}

Information needs - All participants expressed a strong need for more information, at all step of the experiment. They mostly wanted information concerned aspects not covered by the given explanations. This concerned a variety of topics, such as the techniques used by the video analysis, the ground-truth quality and collection method, camera settings, or more evaluation data (e.g., compare with diving observations, apply statistical metrics). Most of the participants expressed the need for means and standard deviations over samples, to visualize error bars. Two participants mentioned that they would ask the help of an expert if the evaluation of the technical details is too complex or too long.

\section{DESIGN IMPLICATIONS}

The video analysis tool is very likely to be accepted by marine biologists for their scientific study, despite the difficulties in understanding and trusting the video processing techniques and the lack of additional provenance information. Marine biologists are used to dealing with uncertainty, as underwater ecosystems are difficult to access and direct observation is often impossible. Their widely-accepted and commonly-used data collection methods can contain significant biases, such as the under-estimation of some species (e.g., diving observation, experimental and commercial fishery). Biologists usually cope with these uncertainties by applying robust statistical methods, by collecting extensive numbers of sample, and by correlating different data sources. The uncertainty of video analysis data is comparable to their usual data collection method. Users can cope with video analysis error rates and imprecise data if the targeted subjects can be observed in a large data collection. Biologists referred to this acceptance of uncertainty as a tradeoff between precision (small magnitude of errors, e.g., small error bar) and accuracy (measurements target the right features, e.g., the right set of species and habitats).

Users need data provenance information that describes both the sampling method and the potential errors in video data. The description of the sampling method supports users in controlling that the targeted subjects can be observed in the collected data. It concerns the coverage of the video collection and of the extracted features. The description of potential errors must support users in differentiating trends from noise in the data, and identifying meaningful patterns. It includes the ROC-like evaluation of video analysis performance, which lead to having users dealing with concepts such False Positive and True Positive, False Alarm Rate and Detection Rate, features vectors and classifiers. These concepts are different from their usual statistical techniques, such as mean and standard deviation. It requires biologists to deal with technical concepts beyond their current

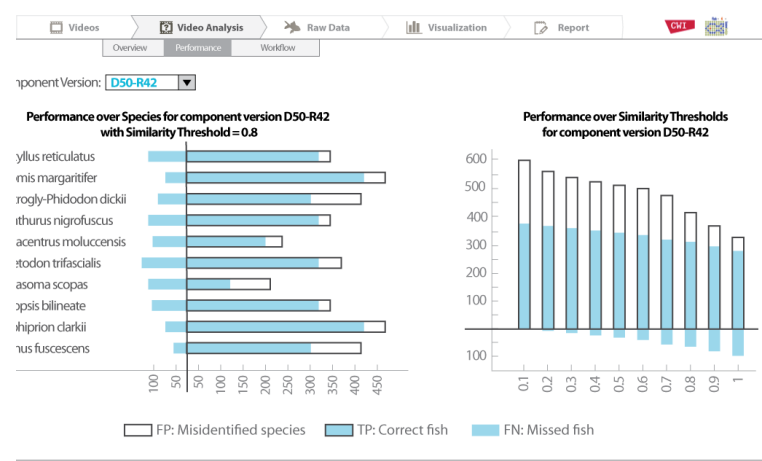

Figure 2: A prototype of our user interface.

expertise. This adds complexity to user tasks and reduces the usability of the video analysis tool. To maintain the usability despite the complex data provenance information, our strategy is to design a user interface that allows users to become experts in understanding how low-level data can provide high-level information, and what video data analysis can be performed. This complex information is delivered by explaining each step of the video processing, thus organizing information in simpler content with a logical structure.

We identified 5 levels of video information processing and interpretation, as shown in Table 4. Each level addresses specific information needs with specific video data, and implies specific uncertainty issues. Each level uses the data processed by lower levels. The identification of these levels of information provides guidelines for the design of the video search tool. When answering user information needs, the video search tool must provide information from the right level(s) of information, and with the data provenance that addresses the uncertainty issues implied at each level. The uncertainty issues related to the sampling method concern mainly the collection of video images on level 1 . The uncertainty issues related to the ROC evaluation concern mainly levels 2 to 3 . The strategy to cope with uncertainty issues depends on each specific user need. It can be applied by visualizing and correlating several sets of relevant data, i.e., at levels 5 and 6 . For instance, it can consist of gathering several fish counts each day at $11 \mathrm{pm}$ and comparing the mean and standard deviation over days and cameras.

These insights were applied in the design of our user interface, as illustrated in Fig. 2 From the identified levels of information, we derived the user interface functionalities needed to answer user information needs. The access to information is organized in 5 tabs. The 1 st tab addresses the 
Table 4: Level of information and related UI functionalities

\begin{tabular}{|l|l|l|l|l|}
\hline Level of Information & Data to analyze & Uncertainty issues & UI tab & UI features \\
\hline 5. Overall Study & $\begin{array}{l}\text { Aggregated visual- } \\
\text { izations }\end{array}$ & $\begin{array}{l}\text { Validity of correla- } \\
\text { tions }\end{array}$ & "Report" & $\begin{array}{l}\text { Group, comment and share vi- } \\
\text { sualizations. }\end{array}$ \\
\hline 4. Visualization & Aggregated counts & $\begin{array}{l}\text { Statistical variability. } \\
\text { Validity of correla- } \\
\text { tions. }\end{array}$ & $\begin{array}{l}\text { "Vaw Data", } \\
\text { tion" }\end{array}$ & $\begin{array}{l}\text { Overview of available data and } \\
\text { possible visualization. Specifi- } \\
\text { cation of adhoc visualizations. }\end{array}$ \\
\cline { 1 - 2 } 3. Fish Species & $\begin{array}{l}\text { Counts of species } \\
\text { and fish per species }\end{array}$ & ROC evaluation & $\begin{array}{l}\text { "Video Anal- } \\
\text { ysis" }\end{array}$ & $\begin{array}{l}\text { Control ROC evaluation, } \\
\text { thresholds of classifiers. }\end{array}$ \\
\hline 2. Fish Detection & Fish counts & $\begin{array}{l}\text { Missing samples. Im- } \\
\text { ages quality. Cam- } \\
\text { eras changes. }\end{array}$ & $\begin{array}{l}\text { Control sampled locations \& } \\
\text { periods. Check cameras set- } \\
\text { ting. Watch video examples }\end{array}$ \\
\hline
\end{tabular}

1st level of information in Table 4, and supports the control of the sampling method used to collect the videos, and the camera settings. The 2 nd tab addresses levels 2-3 by supporting the control of the video processing components involved, the extracted data, and the ROC evaluations. The $3 \mathrm{rd}$ tab provides an overview of the extracted video data and their provenance. It helps users in identifying the information to select for their particular study. The 4 th tab addresses the level 4 and supports user-defined visualization of video data and their provenance. The last tab addresses level 5, and supports manual grouping and annotation of visualizations. With such functionalities, we intend to achieve a user-friendly tool that includes data provenance information addressing the potential biases introduced by the video analysis processes.

\section{CONCLUSION}

We investigated the requirements for a video analysis tool that provides provenance information for scientifically valid analyses of fish counts. Marine biologists performing these analyses are not experts in video processing tools and their technical concepts. We explored their specific needs for data provenance information. Our insights inform the information design of the technical content needed for users to trust the system and accept it for their research. Our main finding is that the statistical methods usually applied in the biology domain are sufficient for biologists to integrate video analysis in their work, even with limited information about ROC evaluation of the software (e.g., without TP, FP and FN). Disclosing the details of video analysis evaluation and ROC measurements is useful to decide on the most appropriate statistical methods. This implies that provenance information must not only concern the ROC evaluation of video analysis components, but also include a review of the sampling method (e.g., sampled location and periods). We propose an organization of a user interface that integrates such provenance information, and that reflects the key aspects of our findings. It will guide the user interface design within the Fish4Knowledge project.

\section{REFERENCES}

[1] D. Artz and Y. Gil. A survey of trust in computer science and the semantic web. Web Semantics: Science, Services and Agents on the World Wide Web, 5(2):58-71, 2007.

[2] E. R. Boose, A. M. Ellison, L. J. Osterweil, L. A. Clarke, R. Podorozhny, J. L. Hadley, A. Wise, and
D. R. Foster. Ensuring reliable datasets for environmental models and forecasts. Ecological Informatics, 2(3):237-247, 2007.

[3] A. Gehani and U. Lindqvist. Veil: A system for certifying video provenance. In Multimedia, 200\%. ISM 2007. Ninth IEEE International Symposium on, pages 263-272. IEEE, 2007.

[4] C. Halaschek-Wiener, J. Golbeck, A. Schain, M. Grove, B. Parsia, and J. Hendler. Annotation and provenance tracking in semantic web photo libraries. Provenance and Annotation of Data, pages 82-89, 2006.

[5] T. Lebo, S. Sahoo, D. McGuinness, K. Belhajjame, J. Cheney, D. Corsar, D. Garijo, S. Soiland-Reyes, S. Zednik, and J. Zhao. Prov-o: The prov ontology. Technical report, 11 December 2012. W3C Candidate Recommendation.

[6] B. Ludäscher, I. Altintas, C. Berkley, D. Higgins, E. Jaeger, M. Jones, E. A. Lee, J. Tao, and Y. Zhao. Scientific workflow management and the Kepler system. Concurrency and Computation: Practice and Experience, 18(10):1039-1065, 2006.

[7] M. Madsen and S. Gregor. Measuring human-computer trust. In Proceedings of Eleventh Australasian Conference on Information Systems, pages 6-8. Citeseer, 2000.

[8] C. Mair, G. Kadoda, M. Lefley, K. Phalp, C. Schofield, M. Shepperd, and S. Webster. An investigation of machine learning based prediction systems. Journal of Systems and Software, 53(1):23-29, 2000.

[9] D. J. McAllister. Affect-and cognition-based trust as foundations for interpersonal cooperation in organizations. Academy of management journal, pages 24-59, 1995.

[10] T. Oinn, M. Addis, J. Ferris, D. Marvin, M. Senger, M. Greenwood, T. Carver, K. Glover, M. R. Pocock, A. Wipat, et al. Taverna: a tool for the composition and enactment of bioinformatics workflows. Bioinformatics, 20(17):3045-3054, 2004.

[11] Y. L. Simmhan, B. Plale, and D. Gannon. A survey of data provenance in e-science. SIGMOD Rec., 34(3):31-36, Sept. 2005.

[12] L. R. Ye and P. E. Johnson. The impact of explanation facilities on user acceptance of expert systems advice. Mis Quarterly, pages 157-172, 1995. 